\title{
Respiratory illness in families of preterm infants with chronic lung disease
}

Leiden University Department of Paediatrics $\mathrm{J} P$ de Winter

I T Merth

$\mathrm{F}$ van Bel

Department of Physiology

$\mathrm{J} P$ de Winter

$\mathrm{Ph} \mathrm{H}$ Quanjer

\section{Department of} Medical Statistics

R Brand

Department of Radiology

H M Zonderland

Academic Medical Center, University of Amsterdam

Department of Neonatology

$\mathrm{L}$ van Sonderen

Department of Paediatrics, Erasmus University and University Hospital, Sophia Children's Hospital, Rotterdam

$\mathrm{J} N$ van den Anker

Correspondence to: Dr J P de Winter, Physiology Department, PO Box 9604

2300 RC Leiden, The

Netherlands.

Accepted 3 August 1995

J P de Winter, L van Sonderen, J N van den Anker, I T Merth, R Brand, F van Bel, $\mathrm{H}$ M Zonderland, $\mathrm{Ph} \mathrm{H}$ Quanjer

\begin{abstract}
Aims-To examine the relation, based on two types of questionnaires, between (1) chronic lung disease of the newborn (CLDN) and lower respiratory illness (LRI) in siblings, and between (2) CLDN and asthma, chronic obstruction pulmonary disease (COPD), or allergy in parents and grandparents.

Methods-Data from 209 children born before 32 weeks of gestation were randomly taken from the records of three neonatal units. Taking into account age and gender, the excess of LRI was calculated for each family compared with the average of all families. Subsequently whether CLDN was associated with an excess of LRI in the family was tested.
\end{abstract}

Results-Thirty one $(14 \cdot 8 \%)$ children were diagnosed as having CLDN. The family probability index for LRI did not differ between children with or without CLDN. The prevalence of COPD, asthma, and allergy in parents of children with CLDN was similar to that of children without CLDN. The prevalence of LRI was $18.1 \%$ in study children, $29.6 \%$ in children with CLDN, and $16.9 \%$ in children without CLDN $(P<0 \cdot 01)$. These prevalences were higher compared with that of a group of term siblings $(9 \cdot 3 \%)(P=0.05)$.

Conclusions-These findings suggest that CLDN in preterm children is not related to a genetic or familial predisposition towards asthma, COPD, or allergy. (Arch Dis Child 1995; 73: F147-F152)

Keywords: preterm infants, respiratory distress syndrome, chronic lung disease of the newborn, asthma.

Chronic respiratory disease is common in both adults and children. Very low birthweight (VLBW) infants are at increased risk of developing chronic respiratory symptoms during the first years of life. Recurrent lower respiratory illnesses (LRI) are common among preterm infants during the first years of life following discharge from a neonatal intensive care unit. ${ }^{1-6}$ Furthermore, an increasing number of VLBW infants develop a respiratory disorder that has several important similarities with chronic obstructive pulmonary disease (COPD) and asthma at an older age. This respiratory disorder in infants has been called bronchopulmonary dysplasia by Northway et $a l,{ }^{7}$ nowadays referred to as chronic lung disease of the newborn (CLDN).$^{8-11} \mathrm{CLDN}$ is thought to be the result of the damaging effects of oxygen, high inflation pressure when on respiratory support, surfactant deficiency, premature lung expansion, patent ductus arteriosus and/or fluid overload. ${ }^{11-13} \mathrm{It}$ has been suggested that the development and/or severity of CLDN may be related, in part, to a genetically determined predisposition to asthma, COPD, or allergy. ${ }^{14}$ In another study it was concluded that a familial predisposition to airway hyperreactivity was related to prematurity and not to the presence of respiratory distress syndrome (RDS) itself. ${ }^{15}$

The aim of the present study was to examine the relation between (1) CLDN and LRI in siblings, and between (2) CLDN and asthma, COPD, and allergy in parents and grandparents, in a random sample of preterm infants. Furthermore, the prevalence of LRI in preterm infants with and without CLDN during the first years of life was investigated and compared with that in their counterparts born at term.

\section{Methods}

Based on an estimated prevalence of LRI of $15 \%$ in children, and an estimated $10 \%$ prevalence of CLDN in preterm infants born at less than 32 weeks of gestational age, roughly 200 children were required to detect an increase of more than $20 \%$ in the prevalence of LRI in children with CLDN (error of $5 \%$ and power of $>85 \%$ )

A total of 238 preterm infants born between 1 January 1989 and 31 December 1990 were randomly taken from the records of neonatal intensive care units of three university hospitals (Academic Medical Center Amsterdam, $n=118$; Erasmus University and University Hospital, Rotterdam/Sophia Children's Hospital, Rotterdam, $n=60$; University Hospital Leiden, $n=60$ ). The study population comprised nine twins (three identical and six non-identical) and one non-identical triplet. Excluded were infants who did not survive the neonatal period.

Pre- and postnatal data were obtained from the chart records. These included gestational age, birthweight, gender, data concerning the presence and severity of RDS after birth - that is, radiological grade of RDS and CLDN, time on mechanical ventilation and supplemental oxygen, presence of complications (air leaks, patent ductus arteriosus), and whether corticosteroids had been given prenatally and surfactant postnatally to the study infants.

Two types of questionnaires were sent to all parents; $74 \%$ were informed by telephone. The first questionnaire contained standardised 
questions on the presence of asthma, chronic bronchitis, allergy among parents and grandparents ${ }^{16}$ and was based on the European Coal and Steel Community questionnaire. The second questionnaire was modified from the World Health Organisation questionnaire for children and contained standardised questions on the presence of LRI in the study group and their term and preterm siblings. ${ }^{17}$ The reliability and reproducibility of these questionnaires, originally developed to be used for interviewing patients, has been established. ${ }^{16} 17$ Language problems in three immigrant families led to questionnaires being translated by an interviewer or by relatives.

\section{DEFINITIONS}

RDS was diagnosed clinically and radiologically. ${ }^{1819}$ Chest $x$ ray pictures were not taken at four weeks of postnatal age in all infants. In the absence of chest $x$ rays we used the oxygen requirement at a postconceptional age of 36 weeks to define CLDN. This is a better predictor of CLDN than the need for oxygen at 28 days, as it also takes into account differences in gestational age. ${ }^{20}$ Chest $x$ rays taken at about 36 weeks of postconceptional age were scored by a paediatric radiologist according to Toce et al. ${ }^{21}$ Baseline respiratory disease in VLBW infants was scored by the severity index developed and validated by Palta et al. ${ }^{22}$ In the absence of chest $x$ rays at specific postnatal ages, we used only the lung function component of the index (arterial $\mathrm{PO}_{2}$, peak inspiratory pressure, and requirement for supplemental oxygen in inspired gas) at 72 hours and at seven days after birth.

The questionnaires contained standardised questions that were clustered for each diagnosis - for example, LRI, asthma, chronic bronchitis, allergic eczema, and allergy. Smoking habits of the parents were surveyed. 'LRI' in children was defined when their parents reported recurrent periods of wheezing with shortness of breath and cough. When parents reported chronic cough the classification LRI was not made.

Adults were classified as having 'asthma' when one or a combination of the following questions were answered affirmatively: (1) Did you ever have periods of wheezing for at least three days a week? (2) Did you ever have recurrent attacks of wheezing with shortness of breath? (3) Do you require specialist care for asthma symptoms? 'COPD' was classified when a combination or one of the following questions was answered affirmatively: (1) Do you usually cough on getting up on most days for three consecutive months or more during the year? (2) Do you usually bring up phlegm from your chest on most days for three consecutive months or more during the year? (3) Do you require specialist care for chronic bronchitis? Adults were classified as allergic when allergic rhinitis or hay fever was present and/or the parents claimed to exhibit pulmonary, nasal, or skin reactions to dust, animals, pollen or food components.

\section{DATA ANALYSIS}

The relation between the presence of CLDN and a family history of COPD, asthma, and allergy was evaluated in two respects:

(1) From the relation between the presence or absence of CLDN in a study child and the probability of LRI in the corresponding family (as estimated from data on siblings within each family);

(2) From the relation between the presence or absence of CLDN in a child and at least one of the parents and/or grandparents with a history of asthma (COPD, allergy).

\section{Family probability index of LRI}

To establish a possible relation between CLDN and LRI, we applied a method by which, effectively, a substitute for LRI in the study child is constructed. This substitute is first shown to be a relevant substitute, and then its relation with CLDN is estimated. By evaluating the probability of LRI (as a function of age and sex) among all siblings of all study children, we can calculate within each family the excess probability - that is, the excess percentage among siblings - of LRI occurring in that particular family compared with other families, adjusted for the actual age and sex distribution observed in each family. This probability is then assumed to represent the excess probability that the study child will develop LRI (because it is equal to the fraction of its siblings who already had developed LRI) compared with the 'average' study child, provided we can establish that this excess probability is a property of the family and not of individual siblings.

\section{Detailed description}

First a logistic regression model was fitted to the data of all siblings of all study children, irrespective of the family they came from. This yields a 'formula' which allows the probability of LRI to be calculated as a function of age and sex in the entire population of siblings as a kind of reference function. This function was then applied to the siblings within each family separately, thus obtaining both an observed fraction of siblings with LRI and an expected fraction of siblings with LRI (based on the overall occurrence of LRI, taking into account age and sex). The difference between what was observed and what was expected was therefore very simple to interpret: it is the excess fraction of children (not including the study children) in each family with LRI compared with the incidence of LRI within the average family (adjusted for sex and age differences between families). Multiplying this excess fraction by 100 yields a percentage; this can be seen as an index, indicating the amount of excess occurrence of LRI for each family (a negative index indicating less LRI then expected).

We subsequently assessed whether this index was indeed a property of the family, so that it could be used as a measure for the study child unique to that family; a random effects logistic regression model was therefore fitted to 
the data, now stratified by family, using the statistical package EGRET (version 0.26.6). The statistical test of the random effect in this model (measuring the improvement of the model by accounting for the actual family each sibling belongs to, compared with a model which merely uses the pool of all siblings) is the correct test to assess whether this index is a property of the family rather than the individual.

Finally, clinically relevant analysis was performed: a multivariate analysis of variance which tests whether the average index in the family associated with the study child was different between the subgroups of study children with and without CLDN. If so, the interpretation would be that the siblings of infants with CLDN show significantly more or less excess LRI occurrences than siblings without CLDN, which might lead to the conclusion that the study infants themselves, irrespective of CLDN, have different risks for LRI.

CLDN and prevalence of asthma, COPD, and allergy in parents and grandparents

From the presence or absence of a history of asthma (COPD, allergy) among the parents and/or grandparents) we obtained an estimate of the probability that a particular study child has parents and/or grandparents with a confirmed history of asthma, COPD, or allergy. The relation between the presence of absence of CLDN and asthma, COPD, or allergy among parents and grandparents was studied using the $\chi^{2}$ test. The prevalence of LRI in the study group and its subgroups was compared with the prevalence of LRI in a group of term siblings. Basic group characteristics were compared using unpaired $t$ tests and $\chi^{2}$ tests. For all tests a $P$ value of $<0.05$ was required for significance.

\section{Results}

Twenty nine families, two with and 27 without CLDN children, had moved and their new addresses could not be traced. All other parents returned both questionnaires. A complete set of data including pre- and post-

Table 1 Clinical characteristics of 209 study children

\begin{tabular}{|c|c|c|c|c|c|}
\hline \multirow[b]{2}{*}{ Variable } & \multicolumn{2}{|c|}{$\begin{array}{l}\text { Non-CLDN children } \\
(n=178)\end{array}$} & \multicolumn{2}{|c|}{$\begin{array}{l}\text { CLDN children } \\
(n=31)\end{array}$} & \multirow[b]{2}{*}{ Pvalue } \\
\hline & $n(\%)$ & Mean (SD) & $n(\%)$ & Mean (SD) & \\
\hline $\begin{array}{l}\text { Gestational age (weeks) } \\
\text { Birthweight }(\mathrm{g})\end{array}$ & & $\begin{array}{r}29 \cdot 5(1.6) \\
1266(349)\end{array}$ & & $\begin{array}{r}28 \cdot 0(1 \cdot 7) \\
1047(281)\end{array}$ & $\begin{array}{l}<0.01 \\
<0.01\end{array}$ \\
\hline $\operatorname{Sex}(\mathbf{M} / \mathbf{F})$ & $103 / 75$ & & $17 / 14$ & & NS \\
\hline Prenatal corticosteroids & $80(45)$ & & $6(19)$ & & $<0.01$ \\
\hline $\begin{array}{l}\text { Surfactant } \\
R D S \text { grade }\end{array}$ & $17(10)$ & & $8(26)$ & & \\
\hline Unknown & 0 & & 2 & & \\
\hline Grade 0 & $85(48)$ & & $5(16)$ & & $<0.01$ \\
\hline Grade 1 & 31 & & 3 & & \\
\hline Grade 2 & 36 & & 3 & & \\
\hline Grade 3 & 21 & & 7 & & \\
\hline Grade 4 & 5 & & 11 & & \\
\hline PDA & $35(20)$ & & $18(58)$ & & $<0.01$ \\
\hline Pneumothorax & $11(6)$ & & $1(3)$ & & NS \\
\hline Interstitial emphysema & $4(2)$ & & $2(6)$ & & NS \\
\hline IPPV (duration) & $110(62)$ & & $28(90)$ & & $<0.01$ \\
\hline Day * & & $1(0-5)$ & & $23(9-33)$ & $<0.01$ \\
\hline $\begin{array}{c}\mathrm{O}_{2}>21 \% \\
\text { Day* }\end{array}$ & $148(83)$ & $4(1-14)$ & $31(100)$ & $64(48-82)$ & $\begin{array}{l}<0.05 \\
<0.01\end{array}$ \\
\hline
\end{tabular}

^Median and 25 to 75 th percentiles. RDS grade: radiological grade of RDS according to Giedion, ${ }^{19}$ PDA: patent ductus arteriosus, IPPV: intermittent positive pressure ventilation. natal variables and returned questionnaires was obtained from 209 (88\%) infants; however, some questionnaires were incomplete. Table 1 shows the characteristics of the 209 infants. Thirty one $(14 \cdot 8 \%)$ infants were diagnosed as having CLDN confirmed by chest $x$ rays taken at about 36 weeks postconceptional age. The mean radiological severity score for CLDN was 4 . In 13 cases no chest $x$ rays were available at 36 weeks. Infants with CLDN had a significantly lower gestational age and birthweight than controls (table 1). The proportion of infants prenatally treated with corticosteroids was significantly higher in the control group compared with the CLDN group: $45 \%$ $v 19 \%$. RDS was far more common and more severe in the CLDN group than in those who did not develop CLDN: $84 \%$ v $52 \%$. The incidence of PDA requiring therapeutic intervention was significantly higher in the group of infants with CLDN.

In the last period of 1990 two centres took part in international surfactant trials; 25 infants included in the present study received surfactant prophylactically or therapeutically. Twenty eight $(90 \%)$ CLDN infants needed mechanical ventilation with a median duration of 23 days. In the non-CLDN group $62 \%$ of the infants were mechanically ventilated with a median duration of one day. The median duration of supplemental oxygen was four days in the non-CLDN group, and 64 days in the CLDN group.

\section{ANSWERS TO QUESTIONNAIRES \\ Family probability index of LRI}

Questionnaires of $41(10.5 \%)$ children were incomplete with regard to LRI, sex, or age (16 study children and 27 siblings) and were excluded from analysis. As a result the calculation of the family probability index for LRI comprised 193 study children and 158 siblings. Median age (range) of the study children and their siblings was 3 years (2-4) and 4 years (1-23), respectively. Each family averaged two children (range one to seven) and this was comparable between families with and without any children with CLDN $(P=0 \cdot 9)$. The prevalence of LRI was $18 \cdot 1 \%$ in the study children. As expected the prevalence was different between the 27 children with CLDN and the 166 children without CLDN; 29.6 and $16.9 \%$, respectively $(\mathrm{P}<0.01)$ (table 2$)$.

The probability of LRI (as a function of age

Table 2 Results from questionnaires

\begin{tabular}{lcc}
\hline Group & $n=$ & LRI (\%) \\
\hline Study children & 193 & $18 \cdot 1^{\star}$ \\
No CLDN & 166 & $16 \cdot 9$ \\
Without RDS & 80 & $16 \cdot 3$ \\
With RDS & 84 & $17 \cdot 9$ \\
CLDN & 27 & $29 \cdot 6 \dagger$ \\
Without RDS & 5 & $80 \cdot 0$ \\
With RDS & 22 & $18 \cdot 2$ \\
All siblings & 158 & $12 \cdot 0$ \\
Siblings of CLDN children & 27 & $18 \cdot 5$ \\
Siblings of no CLDN children & 131 & $10 \cdot 7$ \\
Term siblings & 86 & $9 \cdot 3$ \\
Siblings of CLDN children & 22 & $13 \cdot 6$ \\
Siblings of no CLDN children & 64 & $7 \cdot 8$
\end{tabular}

$\star \mathrm{P}=0.05 v$ term siblings, $+\mathrm{P}<0.01 v$ no $\mathrm{CLDN}$ children. 
and sex) among all siblings of study children was calculated in an ordinary logistic regression model. This model was then extended with random effects to account for a possible 'family effect'. The associated likelihood ratio test was highly significant $(P<0.01)$, supporting the hypothesis that the probability of LRI is a measure at the family level rather than the individual level - that is, the probability that LRI is more strongly correlated between children in one family compared with children in different families. Thus we associated the difference of observed and expected percentage of LRI siblings with each family as an index for the (unique) study child in each family, reflecting the increased or decreased chance of that study child developing LRI. This index is then used as if it were a true and simple 'measurement' associated with the study child. Obviously study children without any siblings are thus excluded from all analyses.

The family probability index for LRI did not differ between families of children with and without CLDN: $15.8 v 6.9 \%(95 \% \mathrm{CI}$ of the mean difference $-31.5 ; 13.7 \%$ ). The family probability index for LRI was neither related to the duration of supplemental oxygen therapy, to the duration of artificial ventilation, nor to the lung function score according to Palta at 72 hours and seven days $(P=0 \cdot 9)$.

\section{Prevalence of LRI in subgroups of study children} and their siblings

The overall prevalence of LRI in the study children was $18 \cdot 1 \%$ (table 2 ). These children had 1-14 'asthmatic attacks' (median 3) during the past year. Table 2 shows the prevalence of LRI in four subgroups of preterm children: those who developed CLDN with or without prior RDS and those without CLDN with or without RDS. The prevalence was comparable among children without RDS and CLDN $(16 \cdot 3 \%)$, children with RDS but without CLDN (17.9\%), and children with both RDS and CLDN (18.2\%). Four of the five children who developed late onset CLDN had LRI during the past year.

Eighty six siblings were born at term. They were older compared with the study children, and the prevalence of LRI was significantly lower compared with the total study group: $9 \cdot 3$ v $18 \cdot 1 \%(\mathrm{P}=0.05)$.

Occasional wheezing without asthmatic attacks was very common in the study children; $71 \%$ of the parents reported occasional wheezing compared with $55 \%$ in term siblings.

Prevalence of COPD, asthma, and allergy among parents and grandparents

Table 3 shows the prevalence of COPD, asthma, and allergy in the parents. Twenty nine parents were diagnosed as having asthma, nine requiring specialist care. One father but none of the mothers of a child with CLDN was diagnosed as having asthma. No significant differences were found between the groups of children with and without CLDN with regard to the prevalence of COPD and allergy among the parents. The questionnaire also revealed similar prevalences for smoking habits of fathers and mothers of children with and without CLDN.

There were no significant differences in the percentage of grandparents with asthma, chronic bronchitis, allergy or emphysema in the two groups (data not shown).

\section{Discussion}

We investigated familial and/or genetic factors associated with asthma, COPD, and allergy which might contribute to the development of CLDN in premature infants. Only a minority of premature infants develop CLDN; therefore we argued that a propensity to inflammatory airway disease might be a risk factor. No evidence was found that an excess of LRI within a family predisposed preterm infants to developing CLDN. The prevalence of COPD, asthma, and allergy in parents and grandparents of children with or without CLDN was similar. LRI was more prevalent in study children with CLDN compared with those without CLDN. The lowest prevalence of LRI was found in term siblings.

Several other studies have also looked into a genetic or familial association between CLDN and chronic respiratory disease in relatives. ${ }^{14}$ 23-27 The relation between asthma or COPD with CLDN has been investigated because of pathophysiological similarities. As in asthma and COPD, airways resistance is increased and maximal forced expiratory flow at functional residual capacity is decreased in infants with CLDN. ${ }^{28-31}$ Moreover, as in asthma an exaggerated bronchoconstrictor response to pharmacological challenges ${ }^{26}$ and successful bronchodilator treatment have been reported in infants with CLDN. ${ }^{32} 33$ Bronchiolar smooth muscle hypertrophy occurs both in asthma ${ }^{34}$ and in CLDN. ${ }^{13}$ There is airway inflammation in both CLDN and asthma. ${ }^{3536}$ However, there is little

Table 3 Relations between CLDN and parent's history $(n=208)$

\begin{tabular}{|c|c|c|c|}
\hline & $\begin{array}{l}\text { Positive } \\
n=(\%)\end{array}$ & $\begin{array}{l}\text { Negative } \\
n=(\%)\end{array}$ & Pvalue \\
\hline \multicolumn{4}{|l|}{$\begin{array}{l}\text { Asthma } \\
\text { Father }\end{array}$} \\
\hline $\begin{array}{l}\text { No CLDN } \\
\text { CLDN }\end{array}$ & $\begin{array}{r}16(9.9) \\
1(3.3)\end{array}$ & $\begin{array}{r}146(90 \cdot 1) \\
29(96 \cdot 7)\end{array}$ & NS \\
\hline \multicolumn{4}{|l|}{ Mother } \\
\hline $\begin{array}{l}\text { No CLDN } \\
\text { CLDN } \\
\text { COPD }\end{array}$ & $\begin{array}{r}12(7 \cdot 3) \\
0(0 \cdot 0)\end{array}$ & $\begin{array}{c}152(92 \cdot 7) \\
28(100 \cdot 0)\end{array}$ & $<0.05$ \\
\hline \multicolumn{4}{|l|}{$\begin{array}{l}\text { COPD } \\
\text { Father }\end{array}$} \\
\hline $\begin{array}{l}\text { No CLDN } \\
\text { CLDN }\end{array}$ & $\begin{array}{r}24(14 \cdot 1) \\
3(10 \cdot 7)\end{array}$ & $\begin{array}{r}146(85 \cdot 9) \\
25(89 \cdot 3)\end{array}$ & NS \\
\hline \multicolumn{4}{|l|}{ Mother } \\
\hline $\begin{array}{l}\text { No CLDN } \\
\text { CIDN } \\
\text { Allergy }\end{array}$ & $\begin{array}{r}13(7 \cdot 6) \\
2(6 \cdot 9)\end{array}$ & $\begin{array}{r}158(92 \cdot 4) \\
27(93 \cdot 1)\end{array}$ & NS \\
\hline \multicolumn{4}{|l|}{ Father } \\
\hline $\begin{array}{l}\text { No CLDN } \\
\text { CLDN }\end{array}$ & $\begin{array}{r}43(26 \cdot 0) \\
8(27 \cdot 6)\end{array}$ & $\begin{array}{r}122(74 \cdot 0) \\
21(72 \cdot 4)\end{array}$ & NS \\
\hline \multicolumn{4}{|l|}{ Mother } \\
\hline $\begin{array}{l}\text { No CLDN } \\
\text { CLDN }\end{array}$ & $\begin{array}{r}45(26 \cdot 3) \\
8(27 \cdot 6)\end{array}$ & $\begin{array}{r}126(73 \cdot 7) \\
21(72 \cdot 4)\end{array}$ & NS \\
\hline \multicolumn{4}{|l|}{ Smoking } \\
\hline $\begin{array}{l}\text { No CLDN } \\
\text { CLDN }\end{array}$ & $\begin{array}{l}82(46.9) \\
12(40 \cdot 0)\end{array}$ & $\begin{array}{l}93(53 \cdot 1) \\
18(60 \cdot 0)\end{array}$ & NS \\
\hline \multicolumn{4}{|l|}{ Mother } \\
\hline $\begin{array}{l}\text { No CLDN } \\
\text { CLDN }\end{array}$ & $\begin{array}{l}68(38 \cdot 2) \\
10(34 \cdot 5)\end{array}$ & $\begin{array}{r}110(61 \cdot 8) \\
19(65 \cdot 5)\end{array}$ & NS \\
\hline
\end{tabular}


similarity between asthma and CLDN. A typical histological picture in asthma is eosinophilia of the submucosa and airway secretions, and this is not a feature of CLDN. ${ }^{35}$

We calculated the probability of LRI within each family, taking into account the age and sex of all children in each family. The use of this index has potential problems. The index might be biased if age, number of children, and especially the number of preterm infants differed between families with and without a child with CLDN. The age, total number of children, and the proportion of preterm infants within families were similar in both groups. However, the high prevalence of LRI in preterm infants might still bias this index. To circumvent this problem, we excluded the study children when calculating the estimated index for LRI.

A problem of all retrospective studies is potential recall bias attributable to the fact that parents with asthma or parents with a child with CLDN will have a better recall of respiratory symptoms in their children than other parents. Such a bias would have favoured a spurious association between CLDN and familial COPD, asthma, and LRI. This association was not observed, so it is unlikely that a recall bias influenced the results. The relation between parental asthma and the family probability index of LRI illustrates that this index is valuable in identifying families with an abnormally high prevalence of LRI. The diagnosis of wheezing in preschool children from history is difficult. We used the term LRI to describe recurrent wheezy spells with shortness of breath and cough. Recurrent acute episodic wheeze is very common in early childhood. ${ }^{37} 38$ Its causes include infection, allergy, and exposure to atmospheric irritants. The tendency to wheeze is greatest in young children; the occurrence of wheezing associated with respiratory infections decreases with increasing age. ${ }^{39}$ Recently, Martinez et al ${ }^{38}$ reported that $19.9 \%$ of a group of healthy newborns had at least one period of LRI during the first years of life, but most of these children did not wheeze by 6 years of age.

A retrospective survey revealed that persistent or recurrent wheezing occurred twice as frequently in children born prematurely as in those born at term. ${ }^{4}$ Another study revealed a prevalence of $53 \%$ in preterm children during the first year of life. ${ }^{40}$ It has been suggested that this high prevalence is related to a temporary effect of mechanical ventilation on respiratory function. ${ }^{6}$ We found an overall incidence of LRI of $18 \cdot 1 \%$, a value comparable with that found by others. ${ }^{1}$ LRI was significantly more prevalent in prematurely born infants compared with their term siblings. Results from other studies also suggest that preterm birth is associated with an increased risk of developing recurrent wheezing or bronchial hyperreactivity. ${ }^{1-6}$ Von Mutius et al found in their population of 9 to 11 year old schoolchildren that prematurity was associated with asthma. Premature children who required mechanical ventilation were more likely than term children to have a family history of asthma. ${ }^{41}$ This was associated with decreased lung function in preterm children at school age.

It is unclear whether recurrent acute episodic wheezing is related to the development of asthma later on. The tendency for wheezing in preterm infants might arise from a combination of a small airway diameter and viral infections. Airways size increases with age and the tendency to wheeze in response to viral infections will diminish, unless bronchial hyperreactivity is perpetuated by airway inflammation associated with atopy. ${ }^{42}$ Hence, wheezing in preterm infants during the first year of life is probably not related to recurrent wheezing or bronchial hyperreactivity. ${ }^{1-6}$ Follow up studies are needed to evaluate the persistence of LRI in preterm infants.

As expected, LRI was more common in preterm infants with than without CLDN. This difference was unrelated to parental smoking habits. In general the prevalence of LRI was higher in preterm children than in term siblings. We confirm previous observations that a history of wheezing was related to prematurity. ${ }^{315414344}$

In conclusion, a family history of LRI in children, and asthma, chronic bronchitis, and allergy in parents was not related to the development of CLDN in preterm infants born before 32 weeks of gestational age. Secondly, the prevalence of LRI in 3 year old children who were born before 32 weeks of gestational age was significantly higher compared with their term siblings and the prevalence was related to the severity of respiratory problems after birth. Our findings support the hypothesis that the development of CLDN in preterm infants with RDS is unrelated to a genetic or familial predisposition. The increased prevalence of wheezy illness found in preterm infants is therefore likely to be a consequence of small airway diameter and damage due to barotrauma and oxygen toxicity.

We thank Mrs $\mathrm{H}$ Lion, Mrs $\mathrm{N}$ Delfos, Mrs $\mathrm{P}$ de Coteau and Mr C Ramautar for collecting and processing the data of the children under investigation. This work was supported by grant children under investigation. This work was supported by grant 90.32 from the
Foundation).

1 Lucas A, Brook OG, Cole TJ, Morley R, Bamford MF. Food and drug reactions, wheezing, and eczema in preterm infants. Arch Dis Child 1990; 65: 41 1-5.

2 Riedel F. Long term effects of artificial ventilation in neonates. Acta Paediatr Scand 1987; 76: 24-9.

3 Chan KN, Elliman A, Bryan E, Silverman M. Clinical significance of airway responsiveness in children of low birthweight. Pediatr Pulmonol 1989; 7: 251-8.

4 Yuksel B, Greenough A. Relationship of symptoms to lung function abnormalities in preterm infants at follow-up. Pediatr Pulmonol 1991; 11: 202-6.

5 Todisco $\mathrm{T}$, de Benedictis FM, Iannacci L, Baglioni $S$, Eslami A, Todisco E, et al. Mild prematurity and respiraEslami A, Todisco E, et al. Mild prematurity and

6 Giffin F, Greenough A, Yuksel B. Relationship between lung function results in the first year of life and respiratory morbidity in early childhood in patients born prematurely. Pediatr Pulmonol 1994; 18: 290-4.

7 Northway WH, Rosan RC, Porter DY. Pulmonary disease following respirator therapy of hyaline-membrane disease. N Engl f Med 1967; 276: 357-68.

8 Moores RR, Abman SH. Bronchopulmonary dysplasia: persistent cardiopulmonary sequelae of neonatal respiratory distress and its treatment. Semin Respir Med 1990; 11 140-51.

9 Parker RA, Lindstrom DP, Cotton RB. Improved survival accounts for most, but not all, of the increase in bronchopulmonary dysplasia. Pediatrics 1992; 90: 663-8.

10 Bancalari E. Prediction of abnormal pulmonary follow-up in premature infants; commentaries. Pediatrics 1988; 82: in premat. 
11 Farrell PM, Zimmerman JJ. Bronchopulmonary dysplasia. Current Opinion in Pediatrics 1992; 4: 410-6.

12 Bancalari E, Sosenko I. Pathogenesis and prevention of neonatal chronic lung disease: recent developments. Pediatr Pulmonol 1990; 8: 109-16.

13 O'Brodovich HM, Mellins RB. Bronchopulmonary dysplasia. Unresolved neonatal acute injury. $A m$ Rev Respir Dis 1985; 132: 694-709.

14 Nickerson BG, Taussig LM. Family history of asthma in infants with bronchopulmonary dysplasia. Pediatrics 1980; 65: $1140-4$.

15 Bertrand JM, Riley SM, Popkin J, Coates AL. The longterm pulmonary sequelae of prematurity: the role of familial airway reactivity and the respiratory distress syndrome. $N$ Engl $\mathcal{F}$ Med 1985; 312: 742-5.

16 Van der Lende R, Jansen-Koster EJ, Knijpstra S, Meinesz AF, Wever AMJ, Orie NGM. Definition of CARA in AF, Wever AMJ, Orie NGM. Definition of CARA in
epidemiology and preventive medicine. Ned Tijdschr epidemiology and preventive

17 Kerrebijn KF, Hoogeveen-Schroot HCA, Wal MC Van der. Chronic nonspecific respiratory disease in children, a five year follow-up study. Acta Paediatr Scand 1977; (suppl 261): 30-3.

18 Giedion A, Haefliger H, Dangel P. Acute pulmonary X-ray changes in hyaline membrane disease treated with artificial ventilation and positive end-expiratory pressure. Pediatr Radiol 1973; 1: 145-52.

19 Walti H, Couchard M, Relier JP. Neonatal diagnosis of respiratory

20 Shennan AT, Dunn MS, Ohlsson A, Lennox $K$, Hoskins EM. Abnormal pulmonary outcomes in premature infants: prediction from oxygen requirement in the infants: prediction from oxygen requirem
neonatal period. Pediatrics $1988 ; 82: 527-32$.

21 Toce SS, Farrell PM, Laevitt LA, Edwards DK. Clinical and roentgenographic scoring system for assessing bronchopulmonary dysplasia. Am $\mathcal{F}$ Dis Child 1984; 138 581-5.

22 Palta M, Gabberts D, Fryback D, Widjaja I, Peters ME, Farrell $\mathrm{P}$, et al. Development and validation of an index for scoring baseline respiratory disease in the very low birth weight neonate. Pediatrics 1990; 86: 714-21.

23 Gerhardt T, Hehre D, Feller R, Reifenberg D, Bancalari E. Serial determinations of pulmonary function in infants with chronic lung disease. $₹$ Pediatr 1987; 110: 448-56.

24 Bader D, Ramos AD, Lew CD, Platzker ACG, Stabile MW Keens TG. Childhood sequelae of infant lung disease: exercise and pulmonary function abnormalities after bronchopulmonary dysplasia. F Pediatr 1987; 110: 693-9.

25 Andréasson B, Lindroth M, Mortensson W, Svenningsen NW, Johnson B. Lung function eight years after neonatal NW, Johnson B. Lung function eight years a
ventilation. Arch Dis Child 1989; 64: 108-13.

26 Smyth JA, Tabachnik E, Duncan WJ, Reilly BJ, Levison H. Pulmonary function and bronchial hyperreactivity in long term survivors of bronchopulmonary dysplasia. Pediatrics 1981; 68: 336-40.

27 Northway WH, Moss RB, Carlisle KB, Parker BC, Popp RL, Pitlick PT, et al. Late pulmonary sequelae of bronchopulmonary dysplasia. $N$ Engl f Med 1990; 323: 1793-9.
28 Loeber N, Morray J, Kettrick R, Downes J. Pulmonary function in chronic respiratory failure of infancy. Crit Care Med 1980; 8:596-601.

29 Godfrey S, Bar-Yishay E, Arad I, Landau LI, Taussig LM. Flow-volume curves in infants with lung disease. Pediatrics 1983; 72: 517-22.

30 Kao L, Warburton D. Effects of oral diuretics on pulmonary mechanics in infants with chronic bronchopulmonary dysplasia: result of a double-blind crossover sequential trial. Pediatrics 1984; 74: 437-49.

31 Tepper RS, Morgan WJ, Cota K, Taussig LM. Expiratory flow limitation in infants with bronchopulmonary dysplasia. F Pediatr 1986; 109: 1040-6.

32 Brundage KI, Mohsini KG, Froese AB, Fisher JT. Bronchodilator response to ipratropium bromide in infants with bronchopulmonary dysplasia. Am Rev Respir Dis 1990; 142: 1137-42.

33 Stefano IL, Bhutani VK, Fox WW. A randomized placebocontrolled study to evaluate the effects of oral albuterol on pulmonary mechanics in ventilator-dependent infants at risk of developing BPD. Pediatr Pulmonol 1991; 10: 183-90.

34 Dunnil MS, Massarella GR, Anderson LA. A comparison of the quantitative anatomy of the bronchi in normal subjects, in status asthmaticus, in chronic bronchitis and in emphysema. Thorax 1969; 24: 176-9.

35 Bonikos DS, Bensch KG. Pathogenesis of bronchopulmonary dysplasia. In: Merritt TA, Northway WH, Boynton BR, eds. Contemporary issues in fetal and neonatal medicine. Bronchopulmonary dysplasia. Boston: Blackwell Mcientific Publications, 1988: 33-50.

36 Stenmark KR, Westcott JY, Henson PM, Murphy RC. Potential role of eicosanoids and PAF in the pathoPotential role of eicosanoids and PAF in the patho-
physiology of bronchopulmonary dysplasia. Am Rev physiology of bronchopulm

37 Luyt DK, Burton P, Brooke AM, Simpson H. Wheeze in preschool children and its relation with doctor diagnosed asthma. Arch Dis Child 1994; 71: 24-30. 38 Martinez FD, Wright AL, Taussig LM, Holberg CJ, the first year of life. N Engl f Med 1995; 332: 133-8.

39 Kuikka L, Reijonen T, Remes K, Korppi M. Bronchial asthma after early childhood wheezing: a follow-up until 4.5-6 years of age. Acta Paediatr Scand 1994; 83: 744-8.

40 Greenough A, Yuksel B, Maconochie I. Recurrent respiratory symptoms in the first year of life following preterm tory symptoms in the first year of life follon
delivery. $\mathcal{F}$ Perinat Med 1990; 18: 489-94.

41 Von Mutius E, Nicolai T, Martinez FD. Prematurity as a risk factor for asthma in preadolescent children. $\mathcal{F}$ Pediatr 1993; 123: 223-9.

42 Burr ML, Limb ES, Maguire MJ, Amarah L, Eldridge BA, Layzell JCM, Merrett TG. Infant feeding, wheezing, and allergy: a prospective study. Arch Dis Child 1993; 68: 724-8.

43 Edwards DK, Dyer WM, Northway WH. Twelve years' experience with bronchopulmonary dysplasia. $\mathcal{F}$ Pediatr 1977; 59: 839-46.

44 Cooke RWI. Factors associated with chronic lung disease in preterm infants. Arch Dis Child 1991; 66: 776-9. 